\title{
Cross-cultural adaptation, validity, and reliability of the Chinese version of the Nurses' Perceptions of Disaster Core Competencies Scale (NPDCC)
}

\author{
Xue-E Fang ${ }^{1 \#}$, Dan-Ping Chen ${ }^{1 \#}$, Kang-Yao Cheng ${ }^{2 \#}$, Yan-Jun Mao ${ }^{1}$, Min Lu ${ }^{1}$, Ling-Ling Tang ${ }^{1}$, \\ Gulcan Taskiran Eskici ${ }^{3}$
}

${ }^{1}$ Department of Tuberculosis, Shanghai Pulmonary Hospital affiliated to Tongji University, Shanghai, China; ${ }^{2}$ College of Nursing, Shanghai University of Traditional Chinese Medicine, Shanghai, China; ${ }^{3}$ OMU Faculty of Health Sciences, Nursing Department, Department of Nursing Administration, Ondokuz Mayis University, Faculty of Health Sciences, Kurupelit, Samsun, Turkey

Contributions: (I) Conception and design: XE Fang, YJ Mao, DP Chen, KY Cheng, GT Eskici; (II) Administrative support: YJ Mao; (III) Provision of study materials or patients: YJ Mao, DP Chen; (IV) Collection and assembly of data: XE Fang, KY Cheng, M Lu, LL Tang; (V) Data analysis and interpretation: KY Cheng, XE Fang; (VI) Manuscript writing: All authors; (VII) Final approval of manuscript: All authors.

\#These authors contributed equally to this work.

Correspondence to: Yan-Jun Mao. Department of Tuberculosis, Shanghai Pulmonary Hospital Affiliated to Tongji University, No. 507 Zheng-Min Road, Yangpu District, Shanghai, China. Email: maoyanjun_fk@tongji.edu.cn.

Background: In recent years, disasters occurred frequently all over the world, and the role of nurses in public health emergencies and disaster emergencies was highlighted under the background of the covid19 epidemic. However, there was a lack of education and evaluation. Our study aims to cross-cultural adapt the Nurses' Perceptions of Disaster Core Competencies Scale (NPDCC) and evaluate the reliability and validity of the Chinese version.

Methods: We translated the scale following the translation-integration-back translation-expert review procedure, adapted according to Chinese culture. We evaluated the reliability and validity of the scale, and a total sample of 911 nurse data from the Yangtze River Delta Regional Nursing Alliance Hospital was gathered.

Results: The Chinese version of NPDCC included 45 items, 5 factors (critical thinking skills, special diagnostic skills, general diagnostic skills, technical skills, and communication skills) were extracted from the analysis, which could explain the $68.289 \%$ of the total variance. The content validity index was 0.925 . The Cronbach's $\alpha$ of the total NPDCC score was 0.978 , and $0.884-0.945$ for every factor. The split-half for the scale was 0.930 , and every factor was $0.861-0.894$.

Conclusions: The Chinese version of NPDCC has excellent reliability and validity, and it is suitable to measure nurses' perceptions of disaster core competencies in China. The next step is to promote the application in a large scale.

Keywords: Disaster nursing; disaster preparedness; nurses; public emergency; core competencies; reliability; validity

Submitted Jun 29, 2020. Accepted for publication Sep 04, 2020.

doi: 10.21037/apm-20-1454

View this article at: http://dx.doi.org/10.21037/apm-20-1454 


\section{Introduction}

Public emergencies refer to natural disasters, accident disasters, public health events, and social security events that occur suddenly and cause or may cause serious social hazards and require emergency response measures. The government of China refers to all disasters as "public emergencies" and divides them into four categories: natural disasters, accident disasters, public health events, and social security events (1). Public emergencies have frequently occurred, including severe acute respiratory syndrome (SARS) in 2003, human avian influenza in 2005, influenza A (H1N1) in 2010, avian influenza A (H7N9) in 2013, Ebola hemorrhagic fever in 2014, the Middle East respiratory syndrome (MERS) in 2015, and COVID19 in 2019 have emerged in the recent years. With COVID19, according to the global data released on the official website of the World Health Organization on July 15, 13,150,645 people have been confirmed, and 574,464 people have died (2). These emergencies have seriously threatened the health and economic development of people all over the world. Nurses are the leading force in the rescue of public emergencies, and the core emergency response ability directly affects the quality of the entire medical rescue, of considerable significance to the protection of public health, social stability and economic development (3). WHO claimed that nurses provide care in emergency settings and will be key to the achievement of universal health coverage (4). But global disaster nursing education and research is lacking now $(5,6)$. The survey results by Jolyon May indicate that nurses' participation is obviously less than doctors' in the course of disaster management and training, and the degree of attention to disaster response ability is not enough (7). Recently, Chinese scholars have studied the strategies of nurses to cope with public emergencies, but there are insufficient specific measurement tools for nurses' core capacity of disaster preparedness. Applicable to the evaluation of nurses, Turkish scholar Celik (8) developed and validated the Nurses' Perceptions of Disaster Core Competencies Scale (NPDCC) according to International Nursing Coalition for Mass Casualty Education (INCMCE) Disaster preparedness framework in 2010. The scale has 45 items and five subscales: Critical Thinking Skills, Special Diagnostic Skills, General Diagnostic Skills, Technical Skills and Communication Skills. This is a Likert-type scale where each item is scored from 1 point for 'This needs to be taught' to 5 points for 'I can do and teach it'. Minimum and maximum scores vary between 45 and 225 . High scores signify higher perceptions of disaster core competencies. However, its adaption into the Chinese language has not been done yet. This study aims to translate the English version of NPDCC into Chinese combining with Chinese nurses' status and cultural background and to test its reliability and validity among nursing staff, and to provide a reliable and practical measurement tool for assessing the core competence of nurses' public emergency in China. At the same time, it is hoped that the promotion and application of assessment tools can arouse the attention of the global health system on the education and training of emergency response ability of nurses. We present the following article in accordance with the SURGE reporting checklist (available at http://dx.doi.org/10.21037/apm-20-1454).

\section{Methods}

The required permission has been obtained from the original author of the English version scale via e-mail. The translation and cultural adaptation were conducted according to the procedure established by Sousa et al. (9). According to the factor analysis sample scale estimation method: the sample size is $5-10$ times of the number of items (10). EFA and CFA samples were separated. So at least 900 samples need to be included. A total of 911 nurses were recruited and completed the questionnaire in the Yangtze River Delta Regional Lung Disease Nursing Alliance Hospital (35 hospitals, covering 5 provinces) from February to March 2020. These hospitals are all tertiary hospitals, which require nurses to master the ability of disaster care. This study was conducted according to the Declaration of Helsinki (as revised in 2013) principles and the ethics was approved by the institutional review board of Shanghai Pulmonary Hospital (ethical ID number: K19146). Informed consent was obtained from all individual participants included in the study.

\section{Subjects}

The inclusion criteria are as follows:

(I) Obtained a nurse qualification certificate;

(II) A nurse working in a clinical department for at least one year;

(III) Informed and agreed to take part in this research. The exclusion criteria are as follows:

(I) Practitioner nurses;

(II) Training nurses;

(III) Those who were out-of-post during the 
investigation;

(IV) Logistics or auxiliary department nurses.

\section{Instrument}

Celik et al. (8) developed and confirmed the NPDCC for these disaster competencies and literature of INCMCE. The scale has 45 items and five factors: critical thinking skills, special diagnostic skills, general diagnostic skills, technical skills, and communication skills (Table S1). The scale is Likert-type, where each item is scored from 1 point for 'this needs to be taught' to 5 points for 'I can do it and teach it.' Minimum and maximum scores vary between 45 and 225. High scores signify higher perceptions of disaster core competencies. Celik et al. (8) reported that the alpha coefficients of the subscales to vary between 0.81 and 0.92 and is 0.96 for the total scale.

\section{Translation and cultural adaptation}

We obtained permission to translate the English version of the scale into Chinese from the authors using forward and back-translation with reconciliation by a panel of experts. Two English-speaking nursing professionals translated the original questionnaires into Chinese versions, and then the research team discussed and merged the two translations to form a Chinese NPDCC. Two postgraduate English majors who are unfamiliar with the original scale and have bilingual abilities translated the Chinese translation of NPDCC back to English NPDCC. Finally, the expert group compared the back-translated version of NPDCC with the original English scale. The sentences that do not conform to the Chinese cultural background and customs were discussed and changed by members of the research group. The scale is less influenced by cross culture, and the definitions involved are basically the same

Forty-five nurses from Shanghai Pulmonary Hospital were selected to conduct a pilot study to understand the respondents' understanding of the content of the scale and the problems and suggestions during the filling. With the feedback from the survey respondents and the recommendations of the expert group, the Chinese version of NPDCC was appropriately formed in the definitive version. According to the pre-survey results, the scale was adjusted as follows: The item 23 of Original scale" I can explain the psychological effects of the disaster ......" is adjusted as "I can assess and diagnose the psychological effects of the disaster ......"; The item 45 of Original scale" I can explain the appropriate coping strategies to provide support for myself and others against negative effects of disasters" is adjusted as "I can explain how to adopt appropriate coping strategies to help myself and others to resist the negative effects of public health emergencies".

\section{Statistical analysis}

SPSS software (version 21.0) and Amos software (24.0) were used for the statistical analysis. Descriptive statistics are used to summarize the nurses' demographic characteristics. The analyses were expressed as mean \pm standard deviation and percentages. For the Chinese version NPDCC, assessments of reliability and validity, as well as explanatory factor analysis (EFA), were conducted. Item analysis includes critical ratio and correlation analysis: critical ratio test should reach the significance level, indicating the item has sufficient discrimination, and items should be deleted for the Pearson correlation coefficient below 0.60 (11). The internal consistency and half-split reliability analysis were used for reliability analysis: Cronbach's alpha coefficient measuring the average correlation among the items in the scale was considered excellent for above 0.70 . The split-half reliability coefficients were considered excellent for above $0.60(12,13)$. Validity analysis includes content validity and constructs validity analysis. EFA and confirmatory factor analysis (CFA) are utilized for constructing the validity analysis. The significance level was set at $5 \%(\mathrm{P}<0.05)$.

\section{Results}

The NPDCC was designed as an electronic version through a software named "questionnaire star". After obtaining the consent of the nurses, the questionnaire survey was conducted by scanning the QR (Quick Response) code of the web questionnaire. Nurses can draw a lottery of gifts to thank them for their cooperation in completing the study. Each questionnaire needs to be completed completely, and any missing items will be eliminated. A questionnaire was conducted among 911 nurses, and the response rate (number of valid questionnaires/total number of respondents) was $100 \%$.

\section{Demographic characteristics}

Nurses' mean age was 34.26 and meant the professional experience was 15.54 , most of them were women $(97.1 \%)$, married $(78.27 \%)$, and worked as service nurses $(92.35 \%)$. Other demographic information of the research objects was 
Table 1 Demographic characteristics of nursing staff ( $N=911)$

\begin{tabular}{|c|c|c|}
\hline Characteristics & $\mathrm{n}$ & $\%$ \\
\hline \multicolumn{3}{|l|}{ Gender } \\
\hline Female & 885 & 97.1 \\
\hline Male & 26 & 2.6 \\
\hline \multicolumn{3}{|l|}{ Age } \\
\hline $20-30$ & 381 & 41.82 \\
\hline $31-40$ & 319 & 35.02 \\
\hline $41-50$ & 158 & 17.34 \\
\hline$>50$ & 53 & 5.82 \\
\hline \multicolumn{3}{|l|}{ Professional experience } \\
\hline $1-5$ years & 199 & 21.84 \\
\hline $6-10$ years & 267 & 29.31 \\
\hline $11-15$ years & 143 & 15.70 \\
\hline $16-20$ years & 100 & 10.98 \\
\hline$>20$ years & 202 & 22.17 \\
\hline \multicolumn{3}{|l|}{ Educational degree } \\
\hline Associate degree & 367 & 40.3 \\
\hline Bachelor's degree & 530 & 58.2 \\
\hline Master's degree & 13 & 1.4 \\
\hline Doctorate degree & 1 & 0.1 \\
\hline \multicolumn{3}{|l|}{ Nursing title } \\
\hline Nurse & 229 & 25.1 \\
\hline Nurse supervisor & 340 & 37.3 \\
\hline Nurse in charge & 236 & 25.9 \\
\hline Associate professor of nursing & 87 & 9.5 \\
\hline Professor of nursing & 19 & 2.1 \\
\hline \multicolumn{3}{|l|}{ Infectious disease experience } \\
\hline Yes & 337 & 37 \\
\hline No & 574 & 63 \\
\hline \multicolumn{3}{|c|}{ Other public emergencies experience } \\
\hline Yes & 189 & 20.7 \\
\hline No & 722 & 79.3 \\
\hline \multicolumn{3}{|c|}{ Public emergency training experience } \\
\hline Yes & 569 & 62.5 \\
\hline No & 342 & 37.5 \\
\hline \multicolumn{3}{|l|}{ Hospital level } \\
\hline Tertiary hospital & 649 & 71.2 \\
\hline Secondary hospital & 250 & 27.4 \\
\hline Primary hospital & 12 & 1.3 \\
\hline
\end{tabular}

Table 2 NPDCC scores for total and subscales (N=911)

\begin{tabular}{lcc}
\hline Characteristics & Mean & SD \\
\hline The total score of NPDCC & 133.82 & 32.96 \\
Critical thinking skills (CTS) & 11.47 & 3.44 \\
Special diagnostic skills (SDS) & 15.18 & 4.87 \\
General diagnostic skills (GDS) & 37.41 & 10.10 \\
Technical skills (TS) & 46.64 & 15.51 \\
Communication skills (CS) & 23.14 & 8.83 \\
\hline NPDCC, the Nurses' Perceptions of Disaster Core \\
Competencies Scale.
\end{tabular}

shown in Table 1.

\section{NPDCC scores of nurses}

The NPDCC total score was 133.82 [standard deviation (SD): 32.96], and the critical thinking skills, special diagnostic skills, general diagnostic skills, technical skills, and communication skills scores are presented in Table 2.

\section{Item analysis}

Critical ratio (CR value) was used to evaluate the differentiation of Chinese NPDCC entries. The total NPDCC scores of 911 sample data were ranked in descending order. The first $27 \%$ with the highest score was in the high group, and the last $27 \%$ with the lowest score was in the low group. The results showed that the CR values of all items were greater than 3 and reached the significance level (all $\mathrm{P}<0.01$ ), and the correlation coefficient between the items and the total score of the scale was $0.600-0.800$ (all $\mathrm{P}<0.01$ ), indicating that the items in the scale had high discrimination, so all items in the scale were retained (Table 3).

\section{Reliability}

The Cronbach's alpha of the total NPDCC score was 0.978, and $0.884-0.945$ for the subscales. The split-half for the scale was 0.930 , and for the subscales were $0.861-0.894$ (Table 3).

\section{Validity}

\section{Content validity}

There are no clear recommendations on the number of 
Table 3 Validity and reliability evidence

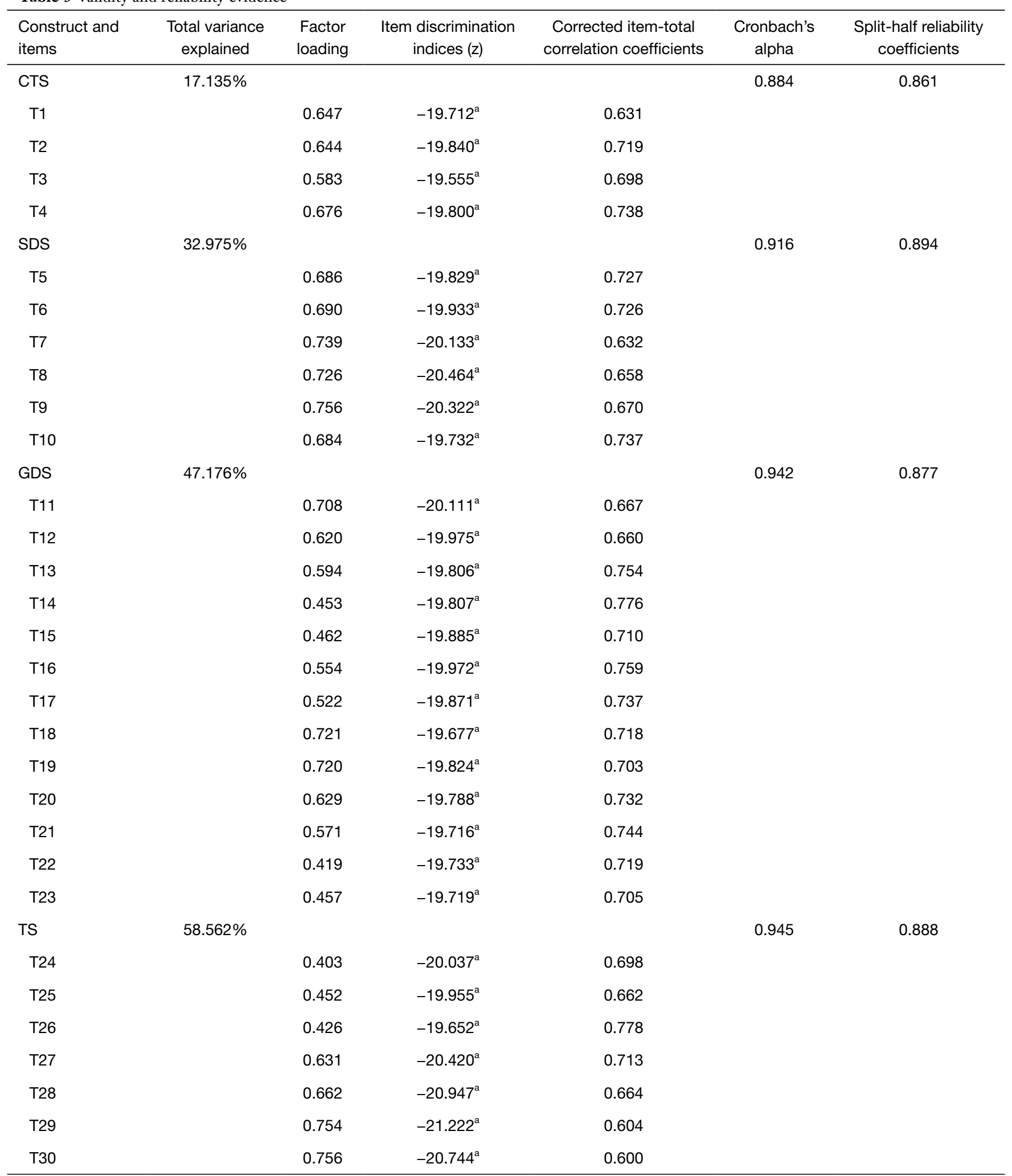

Table 3 (continued) 
Table 3 (continued)

\begin{tabular}{|c|c|c|c|c|c|c|}
\hline $\begin{array}{l}\text { Construct and } \\
\text { items }\end{array}$ & $\begin{array}{l}\text { Total variance } \\
\text { explained }\end{array}$ & $\begin{array}{l}\text { Factor } \\
\text { loading }\end{array}$ & $\begin{array}{l}\text { Item discrimination } \\
\text { indices }(z)\end{array}$ & $\begin{array}{l}\text { Corrected item-total } \\
\text { correlation coefficients }\end{array}$ & $\begin{array}{l}\text { Cronbach's } \\
\text { alpha }\end{array}$ & $\begin{array}{l}\text { Split-half reliability } \\
\text { coefficients }\end{array}$ \\
\hline T31 & & 0.640 & $-19.834^{a}$ & 0.680 & & \\
\hline T33 & & 0.403 & $-19.692^{a}$ & 0.708 & & \\
\hline T34 & & 0.646 & $-19.924^{a}$ & 0.733 & & \\
\hline T36 & & 0.576 & $-20.127^{a}$ & 0.750 & & \\
\hline T37 & & 0.580 & $-19.883^{a}$ & 0.789 & & \\
\hline CS & $68.289 \%$ & & & & 0.941 & 0.914 \\
\hline $\mathrm{T} 41$ & & 0.621 & $-20.038^{a}$ & 0.800 & & \\
\hline T42 & & 0.667 & $-19.633^{a}$ & 0.714 & & \\
\hline T43 & & 0.707 & $-19.676^{a}$ & 0.766 & & \\
\hline T44 & & 0.671 & $-19.516^{a}$ & 0.779 & & \\
\hline T45 & & 0.607 & $-19.824^{a}$ & 0.778 & & \\
\hline
\end{tabular}

a,$P<0.001$. CTS, critical thinking skills; SDS, special diagnostic skills; GDS, general diagnostic skills; TS, technical skills; CS, communication skills.

experts to include. Lynn suggested including a minimum of 3 experts, but more than 10 was not considered helpful (14). Therefore, nursing experts from general or specialist hospitals in Shanghai, Zhejiang, Jiangsu, and Anhui provinces are five members of this research group. They are professors in respiratory medicine, infectious diseases, intensive care unit (ICU), and nursing management. They rated the unambiguity, familiarity, and appropriateness of the items of the CBS-G on a 4-point Likert scale (very unambiguous/familiar/appropriate $=4$; not at all ambiguous/ unfamiliar/inappropriate $=1)(15)$. And the results showed that the content validity index (S-CVI) of the scale was 0.925 , and the content validity index (I-CVI) of each item was $0.800-1.000$.

\section{Construct validity}

\section{EFA for the original five-factor model}

Bartlett's sphericity test $\mathrm{x}^{2}$ value was $4,135.385(\mathrm{P}<0.001)$, and the Kaiser-Meyer-Olkin (KMO) test value was 0.976, indicating that the scale was suitable for factor analysis (16). Using principal component analysis and maximum variance orthogonal study. This method was performed to extract the characteristic value of one or more common factors. The results showed that the characteristic value of one or more common factors with five, the cumulative variance contribution rate was $68.289 \%$, and the scale of various objective factors loading $>0.40$. Further, all entries were in the scope of their respective factors, and these results were the same as the original scale. The exploratory factor analysis results are shown in Table 3.

\section{CFA for the original five-factor model}

We used SPSS AMOS (Version 24.0) to evaluate the research model with the data collected from nursing staff in China. The model produced acceptable fit indices, as shown in Table 4. The results of CFA demonstrated that all scales used in this study formed adequate measurement models, and thus, provided evidence for the construct validity of the measures (17). 
Table 4 Model fit indices

\begin{tabular}{lcc}
\hline Variable & Model & Acceptable values (13) \\
\hline$\chi^{2}$ & $4,006.928$ & $0.05 \leq \mathrm{P} \leq 1.00$ \\
$\mathrm{P}$ value & $<0.001$ & $<3$ \\
$\chi^{2} / \mathrm{df}$ & 4.403 & $<0.08$ \\
Root mean square error of approximation (RMSEA) & 0.061 & $<0.10$ \\
Standardized root mean square residual (SRMR) & 0.0583 & $\geq 0.90$ \\
The goodness of fit index (GFI) & 0.796 & $\geq 0.90$ \\
Tuckere Lewis index (TLI) & 0.907 & $\geq 0.90$ \\
Incremental fit index (IFI) & 0.915 & $\geq 0.90$ \\
Comparative fit index (CFI) & 0.914 & \\
\hline
\end{tabular}

\section{Discussion}

Project analysis is to explore the differences between high- and low-scoring research objects on each item or to evaluate for homogeneity between items. The results can be used as the basis for item selection or modification (18). In this study, the extreme group comparison method and the total score correlation method were used to evaluate each item to screen the Chinese version of the NPDCC scale. The top $27 \%$ of the scale items with the highest score are high grouping, and the bottom $27 \%$ of the scale items are low grouping. The t-test results show that there is statistical significance between the high and low groupings of each item of the scale $(\mathrm{P}<0.01)$. The correlation coefficients between the items and the total scores are all above 0.04 , indicating that all items in the Chinese version of the NPDCC scale have high discrimination, that is, all items have a strong discriminative ability to nurses' core competence in disasters and are retained.

In terms of content validity, if the content validity index of the scale entry is $\geq 0.78$, and the content validity index of the scale is $\geq 0.90$, it can be considered the evaluation tool has good content validity (19). This study evaluated the content validity of the Chinese version of the NPDCC scale by five nursing experts in related fields. After two rounds of expert consultation, the content validity index of the scale was 0.925 , and the content validity index of each item (I-CVI) was over 0.800. The results of this study show that the NPDCC scale indicates that the Chinese version of NPDCC content is valid.

In terms of structural validity, the Chinese version of the NPDCC scale was verified through exploratory factor analysis and CFA, and the common factors were extracted using principal component analysis. A screen diagram of the factor structure was generated, with factor load values and commonness $\geq 0.40$. It can be considered the entry that is in this factor (20). The results of this study show that the cumulative contribution rate of the five common factors of critical thinking skills, special diagnostic skills, general diagnostic skills, technical skills, and communication skills is $68.289 \%$, and the load value of each item on the corresponding factor is $0.403-0.756$. The test results of the original scale are similar and have sufficient structural validity.

Reliability is an effective evaluation of tool stability. The higher the reliability, the greater the credibility (21). The Cronbach's alpha coefficient of each dimension of the scale is $>0.70$, and the Cronbach's alpha coefficient of the total scale is $>0.80$, indicating that the reliability of the scale is excellent $(12,13)$. The results of this study show that the Cronbach's alpha coefficient of the Chinese version of the NPDCC scale is 0.978 , and the Cronbach's alpha coefficients of the subscales are 0.884 to 0.945 ; the halfcoefficient of the scale is 0.930 , and the half-reliability of each dimension is $0.861-0.894$. The Chinese version of the NPDCC scale has high reliability and stability.

G Taskiran used NPDCC to investigate 406 nurses in Turkey. The results show 'Technical Skills' scored highest across the subscales of the scale, and 'Critical Thinking Skills' scored lowest (5). And Park used NPDCC to explore Factors influencing disaster nursing core competencies of emergency nurses working in 12 hospitals in South Korea (22). In this study, we complete Cross-cultural adaptation and test of NPDCC. However, the further application of the 
scale needs further research.

Study limitation: The sample source for reliability and validity verification is relatively single, and it needs to be applied in other areas of China in the follow-up study.

\section{Conclusions}

The NPDCC scale covers five aspects of nurses' core competencies in disasters, which can comprehensively measure the core competencies of nurses in response to disasters. The Chinese version of NPDCC has excellent reliability and validity and meets the requirements of measurement. It shows it is suitable for measuring the cognitive level of the nurse's core public emergency.

\section{Acknowledgments}

Funding: This work was supported by The Fund of basic scientific research business expenses of Tongji University (No. 22120200017), Shanghai, China.

\section{Footnote}

Reporting Checklist: The authors have completed the SURGE reporting checklist. Available at http://dx.doi. org/10.21037/apm-20-1454

Data Sharing Statement: Available at http://dx.doi. org/10.21037/apm-20-1454

Conflicts of Interest: All authors have completed the ICMJE uniform disclosure form (available at http://dx.doi. org/10.21037/apm-20-1454). The authors have no conflicts of interest to declare.

Ethical Statement: The authors are accountable for all aspects of the work in ensuring that questions related to the accuracy or integrity of any part of the work are appropriately investigated and resolved. This study was conducted according to the Declaration of Helsinki (as revised in 2013) principles and the ethics was approved by the institutional review board of Shanghai Pulmonary Hospital (ethical ID number: K19-146). Informed consent was obtained from all individual participants included in the study.

Open Access Statement: This is an Open Access article distributed in accordance with the Creative Commons
Attribution-NonCommercial-NoDerivs 4.0 International License (CC BY-NC-ND 4.0), which permits the noncommercial replication and distribution of the article with the strict proviso that no changes or edits are made and the original work is properly cited (including links to both the formal publication through the relevant DOI and the license). See: https://creativecommons.org/licenses/by-nc-nd/4.0/.

\section{References}

1. Li YH, Li SJ, Chen SH, et al. Disaster nursing experiences of Chinese nurses responding to the Sichuan Ya'an earthquake. Int Nurs Rev 2017;64:309-17.

2. World Health Organization. Coronavirus disease 2019 (COVID-19) Situation Report - 76. Available online: https://www.who.int/docs/default-source/coronaviruse/ situation-reports/20200715-covid-19-sitrep-177. pdf?sfvrsn=b1a193f3_2

3. Tomblin Murphy G, Mackenzie A, Alder R, et al. Pilottesting an applied competency-based approach to health human resources planning. Health Policy Plan 2013;28:739-49.

4. World Health Organization. Nursing and midwifery. Available online: https://www.who.int/news-room/factsheets/detail/nursing-and-midwifery

5. Taskiran G, Baykal U. Nurses' disaster preparedness and core competencies in Turkey: a descriptive correlational design. Int Nurs Rev 2019;66:165-75.

6. Halstead JA. When Disaster Strikes: Are You and Your nursing students prepared? Nurs Educ Perspect 2013;34:213.

7. May J, Colbert D, Rea S, et al. Preparedness and training in staff responding to a burns disaster. $\mathrm{Br} \mathrm{J}$ Nurs 2015;24:918-23.

8. Celik F. Disaster Preparedness Status of Nurses Working at Turkish Red Crescent. Istanbul: Istanbul University Institute of Health Sciences. 2010.

9. Sousa VD, Rojjanasrirat W. Translation, adaptation and validation of instruments or scales for use in cross-cultural health care research: a clear and user-friendly guideline. J Eval Clin Pract 2011;17:268-74.

10. Hair JF, Black WC, Babin BJ, et al. Multivariate data analysis, 7th Edition Prentice Hall 2009:100.

11. Hazar Kanik Z, Gunaydin G, Pala OO, et al. Translation, cultural adaptation, reliability, and validity of the Turkish version of the Penn Shoulder Score. Disabil Rehabil 2018;40:1214-9.

12. Creswell JW. Educational research: Planning conducting 
and evaluating quantitative and qualitative approaches to research (2nd ed.). Upper Saddle River, NJ: Merrill/ Pearson Education, 2005.

13. Fleiss JL. Reliability of measurement. In: Fleiss JL. editor. The Design and Analysis of Clinical Experiments. New York: John Wiley \& Sons, 1986:1-32.

14. Lynn MR. Determination and quantification of content validity. Nurs Res 1986;35:382-5.

15. Holle D, Köller L, Moniz-Cook E, et al. Translation and Linguistic Validation of the German Challenging Behavior Scale for Formal Caregivers of People With Dementia in Nursing Homes. J Nurs Meas 2018;26:544-65.

16. Kaiser HF. A second generation little jiffy. Psychometrika 1970;35:e4015.

17. Arpaci I, Baloglu M. The impact of cultural collectivism on knowledge sharing among information technology majoring undergraduates. Computers in Human Behavior 2016;56:65-71.

Cite this article as: Fang XE, Chen DP, Cheng KY, Mao YJ, Lu M, Tang LL, Eskici GT. Cross-cultural adaptation, validity, and reliability of the Chinese version of the Nurses' Perceptions of Disaster Core Competencies Scale (NPDCC). Ann Palliat Med 2020;9(5):3304-3312. doi: 10.21037/apm-20-1454
18. He W, Bonner A, Anderson D. Translation and psychometric properties of the Chinese version of the Leeds Attitudes to Concordance II scale. BMC Medical Informatics and Decision Making 2015;15:60.

19. Taskiran G, Baykal U. Nurses' disaster preparedness and core competencies in Turkey: a descriptive correlational design. Int Nurs Rev 2019;66:165-75.

20. Fredrickson BL, Branigan C. Positive emotions broaden the scope of attention and thought-action repertoires. Cognition \& Emotion 2005;19:313-32.

21. Lynn MR. Determination and quantification of content validity. Nurs Res 1986;35:382-5.

22. Park HY, Kim JS. Factors influencing disaster nursing core competencies of emergency nurses. Appl Nurs Res 2017;37:1-5.

(English Language Editor: J. Chapnick) 


\begin{tabular}{ll}
\hline Factors & Items \\
\hline $\begin{array}{l}\text { Critical thinking } \\
\text { skills }\end{array}$ & 1. I can use the ethical principles and the nationally approved information in order to decide the actions to be \\
taken and prioritize them in case of a disaster
\end{tabular}

Special diagnostic 5. In the case of a disaster, I can assess the risk situations that can affect the health of mine, my team and the skills In the case of a disaster, I can assess the risk situations, together with the disaster response team
viction

6. I can recognize the possible indications of the situation the group of people, with the same symptoms, is exposed to

7. I can explain the general symptoms and findings of the exposure to the chemical, biological, radioactive, nuclear and explosive substances that threaten human health

8. I can update my knowledge on the chemical, biological, radiological, nuclear and explosive substances in accordance with the up-to-date information

9. I can explain the essential elements (nature, size, limits, duration etc. of the event) required for the assessment of a mass casualty

10. I can determine the groups that may highly likely be affected and require special care (children, elders, people with a suppressed immune system etc.) during the mass casualty

General diagnostic 11. I can get a history of health to assess exposure to chemical, biological, radiological, nuclear and explosive skills substances

12. I can assess the airway patency and respiration

13. I can perform a cardiovascular assessment including the monitoring of the vital signs and the shock signs

14. I can assess the dermatological conditions, especially like injury, burn and eruption

15. I can do pain assess men

16. I can assess the condition of injury from head to foot

17. I can do a general gastrointestinal system assessment including stool sampling

18. I can do basic neurological assessment

19. I can do a basic musculoskeletal system assessment

20. I can do a basic mental, spiritual and emotional state assessment

21. I can assess the immediate and late psychological reactions/responses of the individual, family and community following mass casualty

22. I can refer the victims to the appropriate sources (psychiatrists, psychologists, consultants, and psychiatric nurses etc.) in order to provide psychological support in the disasters

23. I can assess and diagnose the psychological effects of the disaster on the professional disaster response teams (healthcare professionals, firefighters, ambulance personnel, police etc.)

Technical skills 24. I can ensure safe drug management (especially vasoactive and analgesic drugs, oral, subcutaneous, intramuscular and intravenous drug administrations, etc.)

25. I can provide safe vaccinations for the protection of the community health in disasters

26. I know and apply the appropriate nursing interventions against the side effects of the drugs administered

27. I can apply basic first aid practices

28. I can administer oxygen and apply breathing techniques

29. I can insert a urinary catheter

30. I can insert a nasogastric tube

31. I can apply lavage (e.g., eye and wound lavage)

32. I can perform the basic wound care

33. In case of exposure to the chemical, biological, radiological, nuclear and explosive substances, I can start the appropriate isolation and decontamination processes by assessing the needs of the victims, mine and the disaster response team

34. I know and can apply the safety concerns and the use of the personal protective equipment

35. I can choose and use the personal protective equipment as required

36. Taking into account the nature of the exposure factors and/or injuries, I can apply fluid/nutritional therapy in accordance with the medical treatment and follow up the fluid that the patients take in and out

37. I can assess the transfer status of the injured individual and perform preparation, care, and follow-up in such a way to ensure the safety of the patient during the transfer

Communication 38. I know the disaster management system of the institution I work for and I can explain my professional role in the skills emergency plans

39. I can explain the emergency plans at my workplace and the functions of these plans at community, regional (Xiang, Zhen, Xian) and provincial (Sheng and Shi) levels

40. I know and can apply the importance of the security and privacy issues during the intervention of mass casualties

41. I can ensure the appropriate recording of nursing assessments, interventions and care results during and after the mass casualty

42. I can refer applications from patients, the media and other sources to appropriate sources for information about mass casualties

43. I can explain the basic principles of risk communication to be applied for the individuals and groups affected by disaster during a mass casualty

44. I can recognize the fear, panic and stress reactions that the victims, families and disaster response teams can display during a disaster

45. I can explain how to adopt appropriate coping strategies to help myself and others to resist the negative effects of public health emergencies 